\title{
Direitos humanos dos refugiados
}

\author{
Paula de Araújo Pinto Teixeira'
}

\section{Resumo}

O tema das migrações está incluído nas agendas internacional e nacional dos países do globo. O fenômeno da migração sempre existiu; contudo, as guerras, as mudanças climáticas, a globalização, a pobreza, a fome, as catástrofes, o terrorismo e outros fatores trouxeram a necessidade de rediscussão e aprofundamento do tema, que tem reflexo cada vez maior na sociedade. A concessão de refúgio a pessoas vítimas de perseguição sempre foi vista como um exercício de solidariedade mundial, mas, atualmente vemos um retrocesso em relação ao instituto do refúgio, especialmente sob o argumento da priorização da segurança nacional. Tendo em vista que a orientação de todo o ordenamento jurídico e da atuação dos Estados tem como princípio a dignidade da pessoa humana, esse trabalho visa investigar se o refúgio transcende os argumentos invocados pelos Estados para justificar a sua não-concessão. Com esse fim, foram pesquisados artigos, livros e legislação pertinente, para estabelecer conceitos e parâmetros dentro dos quais o tema deve ser tratado. Como resultado, concluímos que a dignidade da pessoa humana deve pautar normas e comportamentos de modo que o refúgio seja visto sob a ótica do indivíduo e não da perspectiva do Estado, em razão da maior vulnerabilidade do primeiro.

Palavras-chave: Refúgio. Vítimas. Perseguição. Proteção. Direitos Humanos. Dignidade da pessoa humana.

\footnotetext{
${ }^{1}$ Advogada. Aluna do Curso de Especialização em Direito Internacional Ambiental (UNI-
} TAR). Pós-graduada em Direito Público (Fortium). Bacharel em Direito (UniCEUB). 


\section{Introdução}

Em razão da intensa discussão, nas últimas décadas, acerca da efetivação dos direitos humanos ${ }^{2}$ dentro e fora das fronteiras dos países, iniciada com a Declaração Universal dos Direitos Humanos de 1948 a temática dos refugiados, em seus vários aspectos, vem ganhando especial atenção das comunidades acadêmica e civil, especialmente após a criação do Alto Comissariado das Nações Unidas para Refugiados (ACNUR), em 1951. Esse artigo busca analisar o aspecto jurídico relacionado aos refugiados no que se refere a seus direitos.

É imprescindível compreender quem são, exatamente, os refugiados, para que então se passe ao exame do corpo de leis e tratados a eles aplicável. Assim, primeiramente, se estabelece o conceito jurídico de refugiado.

Depois, faz-se a diferenciação entre fluxos de migração voluntários e forçados, constatando-se que os refugiados se enquadram neste último tipo de fluxo, o que os torna vulneráveis e vítimas de desrespeito aos seus direitos, razão pela qual necessitam de tratamento especial.

Todavia, apesar dessa constatação, o cenário mundial tem sido, em geral, o de fechamento de fronteiras a migrantes indesejados, categoria da qual fazem parte os refugiados. Os argumentos de que se servem os Estados para justificar esse repúdio ao estrangeiro são de cunho social, econômico, financeiro, político etc. e estão presentes em discursos que reforçam, principalmente, a questão da soberania e da segurança nacional.

Após traçar esse panorama, afirma-se que há uma urgente necessidade de mudança. Nossa tese é a de que o tema do refúgio deve ser visto na esfera de incidência dos Direitos Humanos. Dessa forma, sustenta-se que é aplicável todo o aparato jurídico pertinente a esse ramo do Direito.

\footnotetext{
2 "Os direitos humanos são entendidos como um conjunto de faculdades e instituições que em cada momento histórico concretizam as exigências da dignidade, da liberdade e da igualdade humanas, as quais devem ser reconhecidas positivamente pelos ordenamentos jurídicos em âmbito nacional e internacional."

MILESI, Rosita. Migrantes e refugiados: proteção de seus direitos e resgate da dignidade humana. Disponível em: <http://www.migrante.org.br/artigoloutubro. doc>. Acesso em: 07 out. 2008.
} 
A Declaração Universal dos Direitos Humanos de 1948 foi “o divisor de águas, o marco do processo de internacionalização dos direitos humanos [...] que definiu os novos contornos da ordem pública mundial, baseada, sobretudo, no respeito à dignidade humana"3. Tão relevante o prestígio alcançado pelos direitos humanos que diversos doutrinadores falam em mitigação ou limitação da soberania dos Estados frente ao Direito Internacional dos Direitos Humanos, destacando:

[...] o fortalecimento do sistema internacional de direitos humanos como um contraponto ao conceito de soberania como poder incontrastável nas esferas doméstica e, sobretudo internacional. ${ }^{4}$

Essa nova conformação quebra a lógica do Direito Internacional tradicional que preceitua uma soberania exclusiva, absoluta, "mostrando notáveis indícios de exaustão diante da globalização e das normas jurídicas internacionais"5, notadamente as normas relacionadas a direitos humanos, a direito humanitário e, mais recentemente, a meio ambiente.

Desse modo, reforça-se que, quando há um conflito entre soberanias e direitos individuais insculpidos na Declaração Universal de Direitos do Homem ou em outro documento internacional sobre Direitos Humanos, devem prevalecer os direitos individuais. Ademais, demonstra-se que há direitos humanos a serem aplicados especificamente aos refugiados, especialmente àqueles que estão expressos na Convenção da ONU de 1951, relativa ao Estatuto dos Refugiados. Dentre esses direitos, destaca-se a regra do non-refoulement e a necessidade de elaboração e realização de políticas públicas voltadas a esses migrantes.

Por fim, defende-se que o tema das migrações deve ser visto sob a ótica dos Direitos Humanos. Os argumentos utilizados pelos Estados para repelirem as pessoas que solicitam refúgio não são suficientes para afastar as normas internacionais de direitos humanos e de direitos do refugiado e tampouco para justificar o descumpri-

\footnotetext{
${ }^{3}$ ROCHA. Patrícia Barcelos Nunes de Mattos. Direitos humanos, globalização e soberania. Disponível em: <http://www.fdc.br/Revista/..\%5CArquivos\%5C Revista\%5C21/01.pdf>. Acesso em: 08 out. 2008.

${ }^{4}$ LUZ FILHO, José Francisco Sieber; VIEIRA, Oscar Vilhena. Internacional: soberania e direitos humanos. Disponível em: <http://www2.fpa.org.br/portal/ modules/newsarticle. php? storyid=1263>. Acesso em 10 out. 2008.

${ }^{5}$ CRUZ, Paulo Márcio. Soberania, estado, globalização e crise. Disponível em: <http://www. mundojuridico.adv.br/cgi-bin/upload/texto327.rtf. Acesso em: 11 set. 2008.
} 
mento de seu dever de solidariedade, isso porque a dignidade da pessoa humana é o princípio que deve nortear as normas e a atuação de indivíduos e de nações.

\section{Conceito de refugiado}

Primeiramente, devemos esclarecer quem é "refugiado". O marco jurídico que reconheceu a existência de uma categoria de pessoas denominada "refugiados" foi a Convenção de 1951, relativa ao Estatuto dos Refugiados, adotada em 28 de julho de 1951 pela Conferência das Nações Unidas, que assim os definiu:

Artigo 1 Definição do termo "refugiado":

$\$ 1$. Para os fins da presente Convenção, o termo "refugiado" se aplicará a qualquer pessoa:

a) Que foi considerada refugiada nos termos dos Ajustes de 12 de maio de 1926 e de 30 de junho de 1928, ou das Convenções de 28 de outubro de 1933 e de 10 de fevereiro de 1938 e do Protocolo de 14 de setembro de 1939, ou ainda da Constituição da Organização Internacional dos Refugiados.

b) As decisões de inabilitação tomadas pela Organização Internacional dos Refugiados durante o período do seu mandato não constituem obstáculo a que a qualidade de refugiados seja reconhecida a pessoas que preencham as condições previstas no "\$2 da presente seção".

c) Que, em conseqüência dos acontecimentos ocorridos antes de $1^{\circ}$ de janeiro de 1951 e temendo ser perseguida por motivos de raça, religião, nacionalidade, grupo social ou opiniões políticas, se encontra fora do país de sua nacionalidade e que não pode ou, em virtude desse temor, não quer valer-se da proteção desse país, ou que, se não tem nacionalidade e se encontra fora do país no qual tinha sua residência habitual em conseqüência de tais acontecimentos, não pode ou, devido ao referido temor, não quer voltar a ele.

d) No caso de uma pessoa que tem mais de uma nacionalidade, a expressão "do país de sua nacionalidade" se refere a cada um dos países dos quais ela é nacional. Uma pessoa que, sem razão válida fundada sobre um temor justificado, não se houver valido da proteção de um dos países de que é nacional, não será considerada privada da proteção do país de sua nacionalidade.

$\$ 2$. Para os fins da presente Convenção, as palavras "acontecimentos ocorridos antes de $1^{\circ}$ de janeiro de 1951", do "artigo $1^{\circ}$,

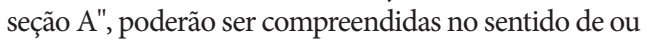


a) "Acontecimentos ocorridos antes de $1^{\circ}$ de janeiro de 1951 na Europa".

b) "Acontecimentos ocorridos antes de $1^{\circ}$ de janeiro de 1951 na Europa ou alhures". ${ }^{6}$

Verifica-se que, na definição dada pela Convenção, há uma limitação “temporal" que exige que os acontecimentos que deram causa à perseguição sofrida pelos refugiados tenham sido anteriores a $1^{\circ}$ de janeiro de 1951 . Todavia, tal limitação foi retirada, graças ao Protocolo sobre o Estatuto dos Refugiados,aprovado em Nova York em 31 de janeiro de $1967^{7}$.

Também podemos verificar a existência de outra limitação, sendo esta “geográfica”, imposta pelo $\$ 2^{\circ}$ do mesmo Artigo. Apesar de não ter sido excluída expressamente pelo Protocolo de 1967, como ocorreu com a limitação "temporal", o aclamado jurista mexicano Jaime Ruiz de Santiago afirma que "de fato, são poucos os Estados que, atualmente, mantêm ainda essa limitação, que reserva o termo 'refugiado' à pessoa que reúna os requisitos da definição e como resultado de acontecimentos ocorridos na Europa" ${ }^{8}$.

Assim, hoje, o conceito de refugiado engloba qualquer perseguição, nos moldes do Artigo $1^{\circ}$, que seja decorrente de quaisquer acontecimentos, não importando a data ou local de ocorrência. Os refugiados são, então, "homens, mulheres e crianças obrigados a deixar sua pátria por fundado temor de perseguição seja por motivo de raça, religião, nacionalidade ou opinião" 9 .

${ }^{6}$ ONU. Convenção de 1951 relativa ao Estatuto dos Refugiados. Artigo primeiro.

${ }^{7}$ DE SANTIAGO, Jaime Ruiz. As três vertentes da proteção internacional dos direitos da pessoa humana.Direitos Humanos, Direito Humanitário, Direito dos Refugiados. 22 abr. 2004. Disponível em: <http://www.icrc.org/web/por/sitepor0. nsf/html/9A61705B9AD3 183303256E7E00617187?OpenDocument\&Style=Custo_Final.3\&View=defaultBody5> Acesso em 14 jun. 2008.

${ }^{8}$ DE SANTIAGO, Jaime Ruiz. As três vertentes da proteção internacional dos direitos da pessoa humana.Direitos Humanos, Direito Humanitário, Direito dos Refugiados. 22 abr. 2004. Disponível em: <http://www.icrc.org/web/por/sitepor0. nsf/html/9A61705B9AD3 183303256E7E00617187?OpenDocument\&Style=Custo_Final.3\&View=defaultBody5> Acesso em 14 jun. 2008.

${ }^{9}$ MILESI, Rosita; CARLET, Flávia. Refugiados e políticas públicas: pela solidariedade, contra exploração. Disponível em: <http://www.migrante.org.br/ refugiados_e_politicas_publicasout06.doc> Acesso em: 16 jun. 2008. 
Esse conceito pode ser alargado pelas legislações nacionais dos Estados assinantes da Convenção ${ }^{10}$. É o que fez, por exemplo, a legislação brasileira, que, com base na declaração de Cartagena (Colômbia, 1984), incluiu a violação a direitos humanos como causa ensejadora da condição de refugiado:

Art. $1^{\circ}$ Será reconhecido como refugiado todo indivíduo que:

I - devido a fundados temores de perseguição por motivos de raça, religião, nacionalidade, grupo social ou opiniões políticas encontre-se fora de seu país de nacionalidade e não possa ou não queira acolher-se à proteção de tal país;

II - não tendo nacionalidade e estando fora do país onde antes teve sua residência habitual, não possa ou não queira regressar a ele, em função das circunstâncias descritas no inciso anterior;

III - devido a grave e generalizada violação de direitos humanos, é obrigado a deixar seu país de nacionalidade para buscar refúgio em outro país. ${ }^{11}$

\section{Migrações forçadas e voluntárias}

Dessa forma, a primeira importante observação é que o refugiado é uma pessoa que se viu forçada a migrar. Dentro das ondas migratórias, podemos distinguir os movimentos voluntários dos forçados. Há quem migre porque quer e quem migre por não ver outra possibilidade de ter um ou mais de seus direitos preservados. Portanto, a migração forçada se caracteriza pela necessidade, por razões de ordem econômica, social, natural ou outras que não estão sob o controle do migrante. ${ }^{12}$

Essa diferenciação se faz importante, pois as migrações forçadas geralmente implicam uma maior vulnerabilidade da pessoa migrante. No caso ainda mais es-

\footnotetext{
${ }^{10}$ ZARATZ, Eduardo et al. Introdução. In: Políticas Públicas para as migrações internacionais: migrantes e refugiados. 2. ed. Brasília: ACNUR; IMDH; CDHM, 2007.

${ }^{11}$ BRASIL. Lei n. 9.474, de 22 de julho de 1997. Define mecanismos para a implementação do Estatuto dos Refugiados de 1951, e determina outras providências. Diário Oficial da União n. 139 - Seção I - p. 15822-15824 23 de julho de 1997.

12 ZARATZ, Eduardo et al. Introdução. In: Políticas públicas para as migrações internacionais: migrantes e refugiados. 2. ed. Brasília: ACNUR; IMDH; CDHM, 2007. p.32.
} 
pecífico dos refugiados, "vulneráveis entre os vulneráveis" ${ }^{13}$, há uma necessidade urgente de lhes garantir um tratamento diferenciado, visto que a não-concessão de refúgio pode lhes causar risco de morte. Luis Varese, representante do ACNUR Alto Comissariado das Nações Unidas para Refugiados - no Brasil, expressa bem essa importância:

Diferenciar um migrante forçado de um refugiado fortalece a pedra angular do refúgio que é o non refoulement, a não devolução. A diferença substantiva é que o refugiado não pode voltar para o seu país sem o risco de ser detido, torturado ou talvez assassinado. ${ }^{14}$

Portanto, impõe-se constatar que o refugiado está inserido em uma classe especial de migrantes forçados, não podendo ser tratado como os demais e menos ainda como um migrante voluntário. O refugiado encontra-se em situação absolutamente perigosa e uma resposta a essa situação é inadiável e indispensável.

\section{0 atual cenário mundial em relação às migrações e ao refúgio}

$\mathrm{Na}$ contramão desse entendimento, o panorama mundial tem sofrido um enrijecimento em relação a normas que dizem respeito à recepção de estrangeiros. Atentados terroristas ocorridos em Nova York, em Madrid, em Londres e em outras cidades mudaram a posição de muitos países em relação aos estrangeiros. Surge uma tendência a "fechar fronteiras" tendo por base um discurso respaldado no combate ao terrorismo, na segurança nacional, na ordem pública e na soberania. ${ }^{15}$

Essa tendência atinge também os refugiados:

Merece acentuado destaque o fato de que, nos últimos anos, emerge de todo esse quadro de violência internacional uma inconseqüente e ineficaz doutrina, sustentada em dois pilares que se retro-alimentam, proporcionando um temerário cenário internacional. Estes pilares são a "Guerra

\footnotetext{
${ }^{13}$ MILESI, Rosita; CARLET, Flávia. Refugiados e políticas públicas: pela solidariedade, contra exploração. Disponível em: <http://www.migrante.org.br/ refugiados_e_politicas_publicasout06.doc $>$. Acesso em: 16 jun. 2008.

${ }^{14}$ VARESE, Luis. Migração e refúgio: o mesmo espaço, tratamento diferenciado. In: Políticas públicas para as migrações internacionais. 2. ed. Brasília: ACNUR; IMDH; CDHM, 2007.

${ }^{15}$ VARESE, Luis. O futuro da cidadania, do refúgio e da migração em debate. In: REFÚGIO, migrações e cidadania. Brasília: ACNUR; IMDH, 2007. p. 9-10. (Caderno de Debates, 2).
} 
ao Terrorismo" e a "Doutrina da Guerra Preventiva". Tais mecanismos doutrinários impositivos, supostamente dedicados a combater o terrorismo, nada mais são do que uma ode à força bruta, um tapa no multilateralismo e uma afronta ao direito internacional público. De início detectam-se duas grandes conseqüências desta doutrina, a serem contabilizadas a médio e longo prazo, capazes de impactar a temática do refúgio: a propagação de um caudal de ódio mundial e a diminuição da disposição dos ditos países ricos que defendem essa doutrina em acolher refugiados e refugiadas de algumas partes do planeta. ${ }^{16}$

Assim, aos refugiados, a classe que mais precisa de aceitação e proteção entre os migrantes, tem sido recusada sua entrada e proteção em países estrangeiros. São eles considerados, muitas vezes, “ameaças à ordem pública, destruidores da identidade nacional, resíduos humanos". ${ }^{17}$ Algumas vezes, sua rejeição e discriminação pelos Estados e pela sociedade se dão pelo desconhecimento do instituto do refúgio que leva a "uma concepção equivocada sobre o indivíduo refugiado, muito vinculado ao migrante irregular ou àquele que cometeu crime em seu país e que buscou proteção em outro". ${ }^{18}$

Nesse contexto, a única exceção de migração ainda bem vista e até estimulada é aquela migração seletiva de que fala Mary Garcia Castro. A especialista afirma que a migração seletiva "estabelece cotas para aqueles e aquelas com especialização profissional em áreas específicas" ${ }^{19}$ e é estimulada "para suprimir necessidades de mão de obra, por um novo darwinismo social, pelo qual se admite apenas os mais aptos"20.

${ }^{16}$ LEÃO, Renato Zerbini Ribeiro. O reconhecimento dos refugiados pelo Brasil: comentários sobre as decisões do CONARE. Brasília: CONAR; ACNUR, 2007. p. 19.

${ }_{17}$ ZARATZ, Eduardo et al. Introdução. In: POLÍTICAS públicas para as migrações internacionais: migrantes e refugiados. 2. ed. Brasília: ACNUR; IMDH; CDHM, 2007. p.14.

${ }^{18}$ QUITO, Marcos Vinícius. O refugiado e o direito à saúde: o Sistema Único de Saúde no fortalecimento do instituto do refúgio. In: REFÚGIO, migrações e cidadania. Brasília: ACNUR, IMDH, 2007. p. 67. (Caderno de Debates, 2).

${ }^{19}$ CASTRO, Mary Garcia. Migração internacional: traspassando fronteiras do nacional e do individual. In: REFÚGIO, migrações e cidadania. Brasília: ACNUR, IMDH, 2007. p. 71. (Caderno de Debates, 2).

${ }^{20}$ CASTRO, Mary Garcia. Migração internacional: traspassando fronteiras do nacional e do individual. In: REFÚGIO, migrações e cidadania. Brasília: ACNUR, IMDH, 2007. p. 71. (Caderno de Debates, 2). 
Antônio Cançado Trindade destaca que a restrição à migração ocorre a despeito da globalização. Isso porque a globalização não atinge pessoas da mesma maneira que atinge bens e serviços:

Em relação ao capital, inclusive o puramente especulativo, o mundo se globalizou, em relação aos seres humanos, inclusive os que tentam fugir de graves ameaças a sua própria vida, o mundo se atomizou em unidades soberanas. ${ }^{21}$

Assim, constata-se que o fechamento de fronteiras a migrantes e a refugiados segue a lógica do mercado e não a do respeito aos Direitos Humanos. É o que se observa em alguns países da Europa que, com o aumento massivo da população de latinos, africanos e de outras origens, vêm adotando políticas e leis extremamente restritivas, sob o argumento de defender seus nacionais em matéria de proteção de mercado e de seguridade social.

Essa forma de exclusão é um mercado lucrativo. Rosita Milesi, destacada especialista no assunto, comenta essa questão:

A quem beneficia a continuidade de uma legislação restritiva quanto ao ingresso dos imigrantes? Esta questão não é meramente retórica, pois, de fato, as quotas de migração e o estabelecimento de critérios elitizados e elitizantes de seleção, ou o fechamento total das fronteiras de um país a determinada nacionalidade produzem diversas distorções:

a) A corrupção de funcionários dos serviços de migração, se não é generalizada, também não se pode afirmar que seja incomum, e isso resulta em favorecimento dos que possuem mais recursos;

b) Todos os tipos de atravessadores, tais como os "coiotes" na fronteira do México com os Estados Unidos, e a formação de uma rede de tráfico de pessoas movimentam uma verdadeira "indústria da migração", onde não há garantias, onde a violência e a morte estão freqüentemente presentes;

c) Nas regiões para onde os imigrantes se dirigem, há um vasto mercado "informal", onde não existem direitos sociais e trabalhistas, os salários estão abaixo da média local e o desemprego é uma ameaça constante; não são

${ }^{21}$ TRINDADE, Antônio A. Cançado. Elementos para um enfoque de direitos humanos acerca do fenômeno dos fluxos migratórios forçados. Guatemala: OIM; IIDH, 2001. (Caderno de Trabalho sobre Migração). 
apenas os bares e pequenas empresas que usam este tipo de mão-de-obra. Empresas de grande porte o adotam confiantes na impunidade ou no silêncio que a condição de imigrantes "ilegais" impõe aos trabalhadores.

d) Beneficia as máfias que trabalham com o tráfico de drogas e a prostituição, torna-se impossível saber quem são os mortos ou desaparecidos, e o lucro é muitas vezes superior ao investimento. Segundo Andrea Freitas, "o tráfico ilegal de imigrantes é um negócio multimilionário que rende entre US\$ 5 bilhões e US 7 bilhões, mais lucrativo e menos arriscado para as máfias do que drogas, armas ou carros roubados. De acordo com a Europol, as máfias do Leste Europeu, especialmente as russas e albanesas, são as principais proprietárias dos negócios. Essas redes têm um aliado: o Tratado de Schengen, que elimina as barreiras físicas para o tráfego de pessoas entre vários países da União Européia (UE), tornando mais difícil o controle dos indocumentados."22

\section{A afronta aos direitos humanos causada pelas políticas restritivas e a necessidade de mudança}

Contudo, esse posicionamento restritivo, de "recrudescimento de políticas imperialistas e unilaterais" propagadas por "um clima de desconfiança e suspeita em relação a todos os estrangeiros" ${ }^{23}$, é contrário aos direitos inscritos na Declaração Universal dos Direitos Humanos de 1948. Quando o tema da migração é abordado, defronta-se com um conflito entre soberanias nacionais e direitos individuais, tais como a vida, a liberdade de ir e vir, entre outros; nesse conflito, os direitos humanos devem prevalecer. Primeiramente, porque diversos instrumentos jurídicos internacionais afirmam a universalidade e a indisponibilidade dos direitos humanos. Depois, em virtude da necessidade de se encarar o fenômeno migratório sob a ótica da família universal, da solidariedade e da cooperação entre os povos ${ }^{24}$.

${ }^{22}$ MILESI, Rosita. Migrantes e refugiados: proteção de seus direitos e resgate da dignidade humana. Disponível em: <http://www.migrante.org.br/artigoloutubro. doc >. Acesso em: 07 out. 2008.

${ }^{23}$ MILESI, Rosita. Migrantes e refugiados: proteção de seus direitos e resgate da dignidade humana. Disponível em: <http://www.migrante.org.br/artigoloutubro. doc >. Acesso em: 07 out. 2008.

${ }^{24}$ ZARATZ, Eduardo et al. Introdução. In: POLÍTICAS públicas para as migrações internacionais: migrantes e refugiados. 2. ed. Brasília: ACNUR; IMDH; CDHM, 2007. p.28. 
Mais que isso, o indivíduo deve estar no centro das discussões. Não se pode olvidar que migração é o fenômeno, mas migrante é a pessoa humana titular de direitos. ${ }^{25}$

\section{1 A declaração universal dos direitos humanos, adotada pela ONU em 1948}

Em virtude de sua condição de seres humanos, é imperativa a aplicação de todos os artigos da Declaração Universal dos Direitos Humanos aos refugiados, dentre os quais se destacam:

\section{Artigo I}

Todas as pessoas nascem livres e iguais em dignidade e direitos. São dotadas de razão e consciência e devem agir em relação umas às outras com espírito de fraternidade.

Artigo II

Toda pessoa tem capacidade para gozar os direitos e as liberdades estabelecidos nesta Declaração, sem distinção de qualquer espécie, seja de raça, cor, sexo, língua, religião, opinião política ou de outra natureza, origem nacional ou social, riqueza, nascimento, ou qualquer outra condição.

Artigo III

Toda pessoa tem direito à vida, à liberdade e à segurança pessoal.

\section{Artigo XIV}

1. Toda pessoa, vítima de perseguição, tem o direito de procurar e de gozar asilo em outros países

2. Este direito não pode ser invocado em caso de perseguição legitimamente motivada por crimes de direito comum ou por atos contrários aos propósitos e princípios das Nações Unidas. ${ }^{26}$

\footnotetext{
25 "A ausência da perspectiva do sujeito é uma das chaves para a crítica da antropologia brasileira aos chamados estudos migratórios [...]”. SPRANDEL, Márcia Anita. A “questão migratória” como objeto de reflexão. In: REFÚGIO, migrações e cidadania. Brasília: ACNUR, IMDH, 2007. p. 36. (Caderno de Debates, 2)

${ }^{26}$ ONU. Declaração Universal dos Direitos Humanos de 1948.
} 
É fundamental a compreensão de que o refugiado é vítima e não ameaça. A resposta ao pedido de asilo deve ser humanitária. António Guterres, representante máximo do ACNUR, em visita ao Brasil, afirmou que o grande desafio do ACNUR e dos governos é lutar pela tolerância, pela discussão de idéias e pela proteção dos refugiados. ${ }^{27}$

O uso do termo "resposta humanitária" para a questão dos refugiados não pode esconder o aspecto jurídico envolvido, em que pese o caráter humanitário ter maior visibilidade. Muitas vezes a obrigação jurídica não é patente porque a Declaração Universal dos Direitos Humanos não fala expressamente em "dever de conceder asilo", apesar de explicitamente mencionar o "direito de buscar asilo". Esse é um dos maiores problemas enfrentados pelos refugiados em relação à Declaração: ao direito de "sair do seu país" não há o correspondente direito de "entrar em outro", motivo pelo qual essas pessoas ficam à mercê da boa vontade de algum Estado em acolhê-los ${ }^{28}$.

Porém, essa responsabilidade dos Estados, tanto social quanto jurídica, é percebida quando da análise da Declaração Universal dos Direitos Humanos e de tantos outros instrumentos internacionais, bem como da legislação interna dos países. Não é necessário que um documento sele esse compromisso das nações em acolher refugiados. Os Estados, apesar de dotados de soberania, devem seguir as diretrizes dos Direitos Humanos, do Direito Humanitário e do Direito dos Refugiados em sua relação com indivíduos, com outros Estados e com a sociedade internacional ${ }^{29}$, em especial aqueles que se dizem democráticos:

Os regimes democráticos devem ter pilares muito sólidos para sustentar-se. Estes pilares de uma sociedade democrática incluem a proteção dos direitos humanos, o Estado de Direito, o devido processo legal, e uma vasta gama de direitos e garantias individuais para a população nacional e também para os estrangeiros residentes no país. 30

${ }^{27}$ BARRETO, Luiz Paulo Teles. O desafio de fortalecer o Direito Internacional dos Refugiados. Refview: a diversidade dos refugiados, Genebra, n. 2, p. 8, mar. 2006.

${ }^{28}$ REIS, Rossana Rocha. Entre a soberania e os direitos humanos: o difícil equilíbrio das políticas de imigração. In: SEMINÁRIO MIGRAÇÕES INTERNACIONAIS E DIREITOS HUMANOS. Anais do... Brasília: CSEM, 2008.

${ }^{29}$ GREGORI, José. Refugiados e imigrantes: uma abordagem de direitos humanos. In: REFÚGIO, migrações e cidadania. Brasília: ACNUR, IMDH. 2007. p. 19. (Caderno de Debates, 2).

${ }^{30}$ BARRETO, Luiz Paulo Teles. O desafio de fortalecer o Direito Internacional dos Refugiados. Refview: a diversidade dos refugiados, Genebra, n. 2, p. 8, mar. 2006. 


\subsection{Os direitos humanos específicos da classe dos refugiados}

Com base nesses paradigmas, podemos afirmar a existência do direito do refugiado de ser oficialmente reconhecido e de obter refúgio quando dele precisar. Cabe ressaltar, no entanto, que o refugiado, quando se encaixe na descrição das normas internacionais, é refugiado antes que um Estado o reconheça como tal, conforme o seguinte entendimento:

Pela Convenção de 1951 sobre Refugiados e outros documentos internacionais, a condição de refugiado existe desde o momento em que uma pessoa cruza uma fronteira devido ao temor de perseguição ou violência. A outorga do status de refugiado é, portanto, um ato declarativo e não um ato constitutivo. ${ }^{31}$

Não obstante, é importante o reconhecimento oficial, ou seja, a concessão do status de refugiado, devido a alguns direitos específicos que daí decorrem. Um deles é a aplicação do princípio do non-refoulement que, nos dizeres de Jaime Ruiz de Santiago, é a "coluna vertebral" do sistema jurídico protetor dos refugiados. ${ }^{32}$ Esse princípio está expresso no Estatuto Internacional de Refugiados:

Artigo 3. Proibição de expulsão ou de rechaço.

$\$ 1$. Nenhum dos Estados Membros expulsará ou rechaçará, de maneira alguma, um refugiado para as fronteiras dos territórios em que a sua vida ou a sua liberdade seja ameaçada em virtude da sua raça, da sua religião, da sua nacionalidade, do grupo social a que pertence ou das suas opiniões políticas.

$\S 2$. O benefício da presente disposição não poderá, todavia, ser invocado por um refugiado que, por motivos sérios, seja considerado um perigo para a segurança do país no qual ele se encontre ou que, tendo sido condenado definitivamente por crime ou delito particularmente grave, constitui ameaça para a comunidade do referido país ${ }^{33}$.

${ }^{31}$ ORELLANA, Xavier. Chegando à população não registrada. Refview: a integração, Genebra, n. 5, mar. 2007.

32 DE SANTIAGO, Jaime Ruiz. As três vertentes da proteção internacional dos direitos da pessoa humana. Direitos Humanos, Direito Humanitário, Direito dos Refugiados. 22 abr. 2004. Disponível em: <http://www.icrc.org/web/por/sitepor0. nsf/html/9A61705B9AD3 183303256E7E00617187? OpenDocument\&Style=Custo_Final.3\&View=defaultBody5 $>$. Acesso em: 14 jun. 2008.

${ }^{33}$ ONU. Convenção de 1951 relativa ao Estatuto dos Refugiados. Artigo terceiro. 
Além do non-refoulement, ou não-devolução, aos refugiados precisam ser garantidos os direitos sociais, econômicos e culturais, mediante políticas públicas voltadas à sua assistência e integração, em especial para garantia do direito à saúde, ao trabalho e à educação ${ }^{34}$. Nesse sentido:

Oferecer refúgio é o primeiro passo, mas não o único. Os países devem oferecer condições para que o indivíduo refugiado possa ingressar na sociedade que lhe oferece abrigo em condições de igualdade com os demais cidadãos do país que o acolhe. ${ }^{35}$

Essa proteção integral e holística é essencial para que o refugiado não se depare com a situação descrita a seguir:

Discriminação, depressão, ansiedade e estigmatização são algumas das situações que enfrentam os refugiados ao fugir de seu país de origem em busca de um lugar seguro. Infelizmente, para muitos deles, estas circunstâncias continuam em suas comunidades de asilo. ${ }^{36}$

Nesse diapasão, impõe-se seguir a orientação do Pacto de São José da Costa Rica, adotado e aberto à assinatura na Conferência Especializada Interamericana sobre Direitos Humanos, em São José de Costa Rica, em 22.11.1969, segundo a qual:

[...] os direitos essenciais da pessoa humana não derivam do fato de ser ela nacional de determinado Estado, mas sim do fato de ter como fundamento os atributos da pessoa humana, razão por que justificam uma proteção internacional, de natureza convencional, coadjuvante ou complementar da que oferece o direito interno dos Estados americanos; ${ }^{37}$

\footnotetext{
${ }^{34}$ MILESI, Rosita; CARLET, Flávia. Refugiados e políticas públicas: pela solidariedade, contra exploração. Disponível em: <http://www.migrante.org.br/ refugiados_e_politicas_publicasout06.doc >. Acesso em: 17 jun. 2008.

${ }^{35}$ QUITO, Marcos Vinícius. O refugiado e o direito à saúde: o Sistema Único de Saúde no fortalecimento do instituto do refúgio. In: REFÚGIO, migrações e cidadania. Brasília: ACNUR; IMDH, 2007. p. 52. (Caderno de Debates, 2).

${ }^{36}$ ECHANDI, Mariana. Da discriminação à integração: refugiados urbanos no México. Refview: a integração, Genebra, n. 5, p. 16, mar. 2007.

${ }^{37}$ CONVENÇÃO Americana de Direitos Humanos de 1969. Preâmbulo. Disponível em: <http://www.pge.sp.gov.br/centrodeestudos/bibliotecavirtual/instrumentos/san jose. htm. Acesso em: 17 jun. 2008.
} 
O refugiado deve, portanto, ser equiparado aos demais nacionais e residentes do país, mas sem deixar de ser atendido em suas particularidades, que por vezes demandam um atendimento psicológico e social diferenciado ${ }^{38}$. Para isso, devem-lhe ser garantidos os direitos esculpidos no Estatuto Internacional dos Refugiados (tais como não-devolução, liberdade religiosa, livre acesso aos tribunais, exercício de atividade profissional assalariada, alojamento, educação, assistência e socorros públicos, liberdade de movimento, documento de identidade, documento de viagem, facilitação da naturalização etc), na Declaração Universal dos Direitos Humanos e nas legislações internas de cada Estado. Acerca do tema, Helio Bicudo escreveu:

E importante assinalar que o migrante é muito mais que um número a ser registrado numa dada estatística ou num trâmite burocrático de documentos na fronteira; é um homem e uma mulher que devem ser respeitados em virtude de sua dignidade enquanto pessoas, muito além do regime vigente ou do lugar onde residem. Seus direitos não derivam do fato de pertencerem a um Estado ou Nação, mas de sua condição de pessoa cuja dignidade não pode sofrer variações ao mudar de um País para outro. Isso significa que um Estado deve dar ao migrante os meios para facilitar sua permanência e possibilitar-lhe um modo de vida digno, onde o migrante, como qualquer outro cidadão nativo, tenha acesso à saúde, à seguridade social e à educação, no caso dos filhos. ${ }^{39}$

Por fim, não se pode olvidar que as políticas públicas não devem ser pensadas somente em relação àqueles refugiados e migrantes que chegam ou tentam chegar aos países de destino. É necessário elaborar e implementar políticas preventivas visando combater os motivos que levam os indivíduos ou grupos sociais a migrarem forçosamente. Como expõe Rosita Milesi:

Necessário e mesmo imprescindível é que se viabilizem políticas públicas nos países de origem para que a migração não seja uma

38 "[...] as rupturas políticas e sociais, as situações de risco e insegurança, o medo e os conflitos culturais intensificam-se nos processos de deslocamento, o que leva à acumulação de um intenso grau, no aparelho psíquico, de excitações [...]." CARIGNATO, Taeco Toma; ROSA, Miriam Debieux; BERTA, Sandra Letícia. Imigrantes, migrantes e refugiados: encontros na radicalidade estrangeira. REMHU: Revista Interdisciplinar da Mobilidade Humana, Brasília, Ano XIV, v. 14, p. 94, n. 26/27, 2006.

${ }^{39}$ BICUDO, Hélio. Migração e políticas públicas. Disponível em: <http://www. dhnet.org.br/ direitos/sos/migrantes/migracao_politicas.htm>. Acesso em 17. jun. 2008. 
necessidade. Ações como o seguro desemprego, programas de renda mínima, geração de postos de trabalho, reforma agrária e urbana, seriam instrumentos efetivos de limitação "natural" do processo migratório, sobretudo da migração forçada. Apoiar e participar de iniciativas como a ação desenvolvida em muitos países para a revisão em torno da Dívida Externa, a conversão destes valores em projetos sociais, o abonar deste peso de origem questionável em muitos países, são atitudes possíveis em nosso âmbito de missão. ${ }^{40}$

\section{Considerações finais}

O tema das migrações deve ser inserido na agenda dos direitos humanos ${ }^{41}$. Encará-lo sob o enfoque da segurança nacional obscurece o lado humano dos migrantes. Rosita Milesi afirma que "as migrações internacionais são uma realidade social e não um problema" ${ }^{42}$ e os ideais humanistas devem ser o palco para o diálogo acerca do tema. A autora afirma categoricamente que "a migração é uma questão social que deve ser tratada no âmbito dos Direitos Humanos" ${ }^{43}$ e jamais com severidade ou segundo as conveniências do mercado.

Rossana Reis salienta:

O estudo da evolução do regime internacional de direitos humanos mostra que é crescente o reconhecimento do indivíduo como portador de direitos independentes de sua nacionalidade, mas, ao mesmo tempo, revela que a implementação destes direitos continua basicamente dependente dos Estados, no caso específico das migrações internacionais, dos Estados receptores. ${ }^{44}$

${ }^{40}$ MILESI, Rosita. Migrantes e refugiados: proteção de seus direitos e resgate da dignidade humana. Disponível em: <http://www.migrante.org.br/artigol outubro.doc > Acesso em: 07 out. 2008.

${ }^{41}$ MILESI, Rosita. Migrantes e refugiados: cidadãos do mundo. In: POLÍTICAS públicas para as migrações internacionais: migrantes e refugiados. 2. ed. Brasília:ACNUR, IMDH e CDHM, 2007. p. 9.

${ }^{42}$ MILESI, Rosita. Migrantes e refugiados: cidadãos do mundo. In: POLÍTICAS públicas para as migrações internacionais: migrantes e refugiados. 2. ed. Brasília:ACNUR, IMDH e CDHM, 2007.p. 9.

${ }^{43}$ MILESI, MILESI, Rosita. Migrantes e refugiados: proteção de seus direitos e resgate da dignidade humana. Disponível em: <http://www.migrante.org.br/artigo1 outubro.doc> Acesso em: 07 out. 2008.

${ }^{44}$ REIS, Rossana Rocha. Soberania, direitos humanos e migrações internacionais. Revista Brasileira de Ciências Sociais, São Paulo, v. 19, n 55, p. 154, jun. 2004. Disponível em: <http://www.scielo.br/pdf/rbcsoc/v19n55/a09v1955.pdf>. Acesso em: 10 out. 2008. 
Dentro do novo paradigma de respeito aos direitos humanos, o Direito Internacional deve assumir, crescentemente, papel central na promoção do direito de proteção da pessoa humana. Antônio Augusto Cançado Trindade ressalta esse ponto:

A nova dimensão do direito de proteção do ser humano, dotado reconhecidamente de especificidade própria, vemse erigindo no plano jurisprudencial sobre o binômio das obrigações de "respeitar" e "fazer respeitar", em todas as circunstâncias, os tratados do direito internacional humanitário e do direito internacional dos direitos humanos. No presente domínio do direito de proteção, tem-se feito uso do direito internacional com o fim de aperfeiçoar e fortalecer - jamais de restringir ou debilitar - o grau de proteção dos direitos humanos consagrados, nos planos tanto normativo como processual. Cumpre continuar explorando todas as possibilidades jurídicas nesse propósito. ${ }^{45}$

\section{Refugees' Human Rights}

\section{Abstract}

The theme of migration is included in international and nation agendas around the globe. The migration phenomenon has always existed; even though, wars, climate changes, globalization, poverty, hunger, catastrophes, terrorism and other factors have brought the need of a profound (re)study about the issue, which has a gradually greater reflex on society. The concession of refuge to the victims of persecution had always been seen as an exercise of international solidarity, but lately we verify a retrocession concerning the institute of refuge, especially under the argument of national security priorization. Considering that the orientation of the legal system and the behavior of the States is based on the principle of the dignity of the human person, this research aims to investigate if the refuge overpasses the arguments brought by the States to justify the denial of refuge concession. To

\footnotetext{
${ }^{45}$ TRINDADE. Antônio Augusto Cançado. As três vertentes da proteção internacional dos direitos da pessoa humana. Direitos Humanos, Direito Humanitário, Direito dos Refugiados. Disponível em: <http://www.icrc.org/web/ por/sitepor0.nsf/html/9A61705B9AD3183303 256E7E00617187? OpenDocument\&Style=Custo_Final.3\&View=defaultBody3.>. Acesso em: 15 jun. 2008.
} 
this purpose, articles, books and pertinent legislation were researched to establish concepts and parameters within which the issue should be addressed. As a result, the conclusion is that the dignity of the human person shall guide rules and actions in such a way that the refuge is seen under the view of the individual and not from the perspective of the State, since the first is more vulnerable.

Keywords: Refuge. Victims. Persecution. Protection. Human Rights. Dignity of the human person

\section{Referências}

BARRETO, Luiz Paulo Teles. O desafio de fortalecer o direito internacional dos refugiados. Refview: a diversidade dos refugiados, Genebra, n. 2, mar. 2006.

BICUDO, Hélio. Migração e políticas públicas. Disponível em: <http://www. dhnet.org.br/ direitos/sos/migrantes/ migracao_politicas.htm>. Acesso em: 17 jun. 2008.

BRASIL. Lei n. 9.474, de 22 de julho de 1997. Define mecanismos para a implementação do estatuto dos refugiados de 1951, e determina outras providências. Diário Oficial da União, Brasília, n. 139, Seção I, p. 15822-15824, 23 jul. 1997.

CARIGNATO, Taeco Toma; ROSA, Miriam Debieux; BERTA, Sandra Letícia. Imigrantes, migrantes e refugiados: encontros na radicalidade estrangeira. REMHU: Revista Interdisciplinar da Mobilidade Humana, Brasília, ano XIV, v. 14, n. 26/27, 2006.

CASTRO, Mary Garcia. Migração internacional: traspassando fronteiras do nacional e do individual. In: REFÚGIO, migrações e cidadania. Brasília: ACNUR, IMDH, 2007. (Caderno de Debates, 2).

CONVENÇÃO Americana de Direitos Humanos de 1969. Adotada e aberta à assinatura na Conferência Especializada Interamericana sobre Direitos Humanos, em San José de Costa Rica, em 22 de novembro de 1969. Disponível em: <http:// www.pge.sp.gov.br/centrodeestudos/bibliotecavirtual/instrumentos/sanjose. htm>. Acesso em 17 jun. 2008.

CRUZ, Paulo Márcio. Soberania, Estado, globalização e crise. Disponível em: <http:// www.mundojuridico.adv.br/cgi-bin/upload/texto327.rtf $>$ Acesso em: 11 set. 2008. 
DE SANTIAGO. Jaime Ruiz. As três vertentes da proteção internacional dos direitos da pessoa humana. direitos humanos, direito humanitário, direito dos refugiados. 22 abr. 2004. Disponível em: <http://www.icrc.org/web/por/ sitepor0.nsf/html/9A61705B9AD3183 303256E7E00617187?OpenDocument\&Style=Custo_Final.3\&View=defaultBody5> Acesso em: 14 jun. 2008.

ECHANDI, Mariana. Da discriminação à integração: refugiados urbanos no México. Refview: a integração, Genebra, n. 5, mar. 2007.

GREGORI, José. Refugiados e imigrantes: uma abordagem de direitos humanos. In: REFÚGIO, migrações e cidadania. Brasília: ACNUR, IMDH, 2007. (Caderno de Debates, 2).

LEÃO, Renato Zerbini Ribeiro. O reconhecimento dos refugiados pelo Brasil: comentários sobre as decisões do CONARE. CONARE e ACNUR. Brasília: CONAR; ACNUR, 2007.

LUZ FILHO, José Francisco Sieber; VIEIRA, Oscar Vilhena. Internacional: soberania e direitos humanos. Disponível em: <http://www2.fpa.org.br/ portal/modules/news/ article.php?storyid=1263>. Acesso em: 10 out. 2008.

MILESI, Rosita. Migrantes e refugiados: cidadãos do mundo. In: POLÍTICAS públicas para as migrações internacionais: migrantes e refugiados. 2. ed. Brasília: ACNUR; IMDH; CDHM, 2007.

- Migrantes e refugiados: proteção de seus direitos e resgate da dignidade humana. Disponível em: <http://www.migrante.org.br/artigol outubro.doc>. Acesso em: 07 out. 2008.

MILESI, Rosita; CARLET, Flávia. Refugiados e políticas públicas pela solidariedade, contra exploração. Disponível em: <http://www.migrante.org. br/refugiados_e_politicas_ publicasout06.doc>. Acesso em: 16 jun. 2008.

ONU. Convenção de 1951 relativa ao Estatuto dos Refugiados. Convocada pela resolução 429 (V) da Assembléia Geral das Nações Unidas, de 14 de Dezembro de 1950.

Declaração Universal dos Direitos Humanos de 1948. Adotada e proclamada pela resolução 217 A (III) da Assembléia Geral das Nações Unidas em 10 de dezembro de 1948.

. Protocolo de 1967 sobre o Estatuto dos Refugiados. Convocado pela resolução 1186 (XLI) de 18 de novembro de 1966 do Conselho Econômico e Social (ECOSOC) e pela resolução 2198 (XXI) da Assembléia Geral das Nações Unidas de 16 de dezembro de 1966. 
ORELLANA, Xavier. Chegando à população não registrada. Refview: a Integração, Genebra, n. 5, mar. 2007.

QUITO, Marcos Vinícius. O refugiado e o direito à saúde: o Sistema Único de Saúde no fortalecimento do instituto do refúgio. In: REFÚGIO, migrações e cidadania. Brasília, ACNUR, IMDH, 2007. (Caderno de Debates, 2).

REIS, Rossana Rocha. Entre a soberania e os direitos humanos: o difícil equilíbrio das políticas de imigração. In: SEMINÁRIO "MIGRAÇÕES INTERNACIONAIS E DIREITOS HUMANOS”. Anais do... Brasília; CSEM, 2008.

. Soberania, direitos humanos e migrações internacionais. Revista Brasileira de Ciências Sociais, São Paulo, v. 19, n. 55, jun. 2004. Disponível em: <http://www.scielo. br/pdf/rbcsoc /v19n55/a09v1955.pdf>. Acesso em: 10 out. 2008.

ROCHA. Patrícia Barcelos Nunes de Mattos. Direitos Humanos, globalização e soberania. Disponível em: <http://www.fdc.br/Revista/..\%5 CArquivos\%5CRevista\%5C21/01. pdf $>$. Acesso em: 08 out. 2008.

SPRANDEL, Márcia Anita. A "questão migratória" como objeto de reflexão. In: REFÚGIO, migrações e cidadania. Brasília: ACNUR; IMDH, 2007. (Caderno de Debates, 2).

TRINDADE, Antônio Augusto Cançado. As três vertentes da proteção internacional dos direitos da pessoa humana. direitos humanos, direito humanitário, direito dos refugiados. Disponível em: <http://www.icrc.org/ web/por/sitepor0.nsf/html/9A61705B9AD3183 303256E7E00617187?Open Document\&Style=Custo_Final.3\&View=defaultBody3 >. Acesso em: 15 jun. 2008.

. Elementos para um enfoque de direitos humanos acerca do fenômeno dos fluxos migratórios forçados. Guatemala: OIM e IIDH, 2001. Caderno de Trabalho sobre Migração.

VARESE, Luis. Migração e refúgio: o mesmo espaço, tratamento diferenciado. In: POLÍTICAS públicas para as migrações internacionais: migrantes e refugiados. 2. ed. Brasília: ACNUR; IMDH; CDHM, 2007.

. O futuro da cidadania, do refúgio e da migração em debate. In: REFÚGIO, migrações e cidadania. Brasília: ACNUR; IMDH, 2007. (Caderno de Debates, 2).

ZARATZ, Eduardo et al. Introdução. In: POLÍTICAS públicas para as migrações internacionais: migrantes e refugiados. 2. ed. Brasília: ACNUR; IMDH; CDHM, 2007. 